1 Fundação Oswaldo Cruz (Fiocruz), Escola Nacional de Saúde Pública Sergio Arouca (Ensp), Centro de Estudos da Saúde do Trabalhador e Ecologia Humana (Cesteh) - Rio de Janeiro (RJ), Brasil. katreis@ensp.fiocruz.br

2 Fundação Oswaldo Cruz (Fiocruz), Escola Nacional de Saúde Pública Sergio Arouca (Ensp), Centro de Estudos da Saúde do Trabalhador e Ecologia Humana (Cesteh) - Rio de Janeiro (RJ), Brasil. andrearodriguesfono@ hotmail.com

3 Universidade Federal Fluminense (UFF) - Niterói (RJ), Brasil. Fundação Oswaldo Cruz (Fiocruz), Escola Nacional de Saúde Pública Sergio Arouca (Ensp), Centro de Estudos da Saúde do Trabalhador e Ecologia Humana (Cesteh) - Rio de Janeiro (RJ), Brasil. veros.fernandez@gmail.com

4 Fundação Oswaldo Cruz (Fiocruz), Escola Nacional de Saúde Pública Sergio Arouca (Ensp), Centro de Estudos da Saúde do Trabalhador e Ecologia Humana (Cesteh) - Rio de Janeiro (RJ), Brasil.

renato.bonfatti@gmail.com

\section{A categoria saúde na perspectiva da saúde do trabalhador: ensaio sobre interações, resistências e práxis}

\author{
The health category in the perspective of worker's health: an essay \\ about interaction, resistances and praxis
}

Katia Reis de Souza1', Andréa Maria dos Santos Rodrigues², Verônica Silva Fernandez ${ }^{\mathbf{3}}$, Renato José Bonfatti 4

RESUMO O principal intento deste ensaio consiste em retomar de modo crítico a perspectiva de saúde sob o enfoque da saúde do trabalhador, reavendo alguns dos seus marcos teóricos constitutivos. Lançou-se mão, como base principal de estudo, de obras seminais pertencentes ao campo, a saber: a medicina social latino-americana e os estudos operários italianos. Além disso, serviram de apoio publicações de autores brasileiros que examinam a configuração teórica, política e metodológica do campo, procurando conferir 'identidade própria' à saúde do trabalhador. Chegou-se a três teses capitais que foram desenvolvidas em diálogo com autores da tradição de pensamento do materialismo histórico.

PALAVRAS-CHAVE Saúde do trabalhador. Socialismo. Categorias de trabalhadores.

\begin{abstract}
The main intention of this essay consists in critically analysing the perspective of health under the focus of worker's health, recovering some of its constitutive theorical milestones. Seminal literature of the field, such as Latin American social Medicine and studies of the Italian workers, was used as a main base of this study. Besides, publications of Brazilian authors, which assess the theorical, political and methodological configuration of the field and seek to provide 'self-identity' to worker's health, also supported this essay. We have come to three capital theses which were developed in dialogues with authors of the tradition of the historical materialism thinking.
\end{abstract}

KEYWORDS Occupational health. Socialism. Occupational groups. 


\section{Introdução}

O campo da saúde do trabalhador emerge no Brasil da área de saúde coletiva para estudo e intervenção nas relações entre saúde, trabalho e ambiente, procurando estabelecer uma estreita articulação com a classe trabalhadora, sobretudo a partir da década de 1980. Resulta, dessa conceituação, uma visão de saúde que se propõe a dar efetividade a um conjunto de saberes e práticas para transformação das condições de exploração do trabalho e para a defesa da saúde dos trabalhadores. No entanto, trata-se de um campo de conhecimento e de práticas ainda não suficientemente delimitado e articulado com a realidade dos trabalhadores, necessitando de reflexão acerca de seus fundamentos e de um arcabouço teórico e de noções mais bem desenvolvidas (LAURELL; NORIEGA, 1989; LACAZ, 1996; MINAYO-GOMEZ, 2011).

Vale lembrar que alguns estudos no campo da relação saúde e trabalho no Brasil foram realizados com a preocupação de realçar as diferenças epistemológicas e ideológicas existentes entre a medicina do trabalho, a saúde ocupacional e a saúde do trabalhador (LACAZ, 1996; MINAYOGOMEZ; LACAZ, 2005; MINAYO-GOMEZ, 2011; MENDES; DIAS, 1991). A importância das análises e das reflexões sucedidas por esses estudos levou ao questionamento a respeito dos marcos teórico constitutivos e das teses que são estruturantes do campo da saúde do trabalhador e seus significados.

Ressalta-se ainda o fato de que, já em 1989, no livro intitulado 'Processo de produção e saúde', os autores Laurell e Noriega observaram que a saúde era a questão menos problematizada no que diz respeito ao campo dos estudos da relação saúde e trabalho. Pontuam que a categoria saúde era vista, de modo geral, conforme a definição da medicina, ou seja, "como um indicador do impacto do trabalho sobre os trabalhadores" (LAURELL; NORIEGA, 1989, P. 99). Nessa linha de interpretação, considera-se, ainda hoje, necessária uma vigilância para não reduzir a categoria saúde unicamente aos processos de adoecimento, riscos e acidente, tal como a saúde ocupacional o faz.
Consoante Laurell e Noriega (1989) e Lacaz (1996), a saúde dos trabalhadores se mostra como um campo privilegiado no que diz respeito, sobretudo, à perspectiva de construir um novo modo de entender e analisar a saúde de coletividades de trabalhadores como processo social. Sendo assim, a forma de teorização deve favorecer as escolhas por categorias críticas de análise e referenciais teóricos que evidenciem aspectos concretos da relação saúde e trabalho, de modo a contribuir para conhecer e, principalmente, transformar a realidade. Para Lacaz e Santos (2010), faz-se mister definir, com todo rigor científico, categorias que busquem interpretar o trabalho na contemporaneidade sob uma perspectiva interdisciplinar, superando a abordagem a-histórica e redutora da saúde ocupacional que restringe o ambiente laboral a fatores de risco de natureza química, física, biológica, mecânica, considerados isoladamente.

Com efeito, a saúde do trabalhador, como campo de práticas e de conhecimento, situa-se no âmago do conflito entre capital e trabalho, demandando categorias analíticas e referenciais, de caráter crítico advindas, sobretudo, da linhagem crítica das ciências sociais. Verificou-se, na literatura do campo, a afirmação recursiva segundo a qual a corrente de pensamento do materialismo histórico exerce posição de destaque como lente de interpretação, filosófica e política, da realidade dos problemas referentes à relação saúde e trabalho (LAURELL; NORIEGA, 1989; LAURELL, 1981; MINAYOGOMEZ; LACAZ, 2005). Neste ensaio, pretende-se desenvolver alguns dos conceitos e teses que se destacam como centrais na literatura, contribuindo para configuração de um aporte teórico próprio do campo da saúde do trabalhador. Para tanto, lançou-se mão, como base principal de estudo, de obras seminais do campo, que conformam uma tradição de pensamento crítico da área da saúde coletiva, a saber: a medicina social latino-americana (LAURELL; NORIEGA, 1989; LAURELL, 1981; GARCIA, 1989) e os estudos operários italianos sucedidos no 
contexto da reforma sanitária daquele país (ODDONE, 1986; BERLINGUER, 1983). Além disso, serviram de apoio publicações de autores brasileiros que examinam a configuração teórica, política e metodológica do campo, procurando conferir 'identidade própria' à saúde do trabalhador (LACAZ, 1996; MINAYO-GOMEZ; LACAZ, 2005; MINAYO-GOMEZ, 2011; MENDES; DIAS, 1991). Formulou-se este ensaio em três seções, partindo de três teses capitais extraídas da literatura de apoio em diálogo com autores da tradição de pensamento do materialismo histórico (MARX, 2013; HARVEY, 2013A, 2013B; LUKÁCS, 2015; SENNETT, 2002; ANTUNES, 2009), quais sejam: a tese da interação metabólica entre saúde, trabalho e ambiente; o processo de trabalho e a resistência de trabalhadores como categorias nodais de explicação da saúde; e, por fim, a tese da saúde como práxis, que trata da relação dialética entre saúde de trabalhadores e a sua capacidade organizativa. Defende-se, neste ensaio, o argumento segundo o qual a concepção de saúde, na perspectiva do campo da saúde do trabalhador, apresenta uma construção teórica própria e original na área da saúde coletiva.

Cumpre a observação de que embora se tenha organizado este ensaio em seções, que ao fim configuram-se como tópicos constitutivos a respeito da categoria saúde no campo da saúde do trabalhador, todos os pontos e teses aqui desenvolvidos encontram-se interligados.

\section{A categoria saúde no ângulo de compreensão das relações saúde, trabalho e ambiente: a tese da interação metabólica}

Distingue-se nas formulações dos autores da medicina social latino-americana (LAURELL; NORIEGA, 1989) a compreensão segundo a qual a categoria saúde adquire um desenvolvimento mais fecundo a partir do enfoque do materialismo histórico. A tese central defendida pelos autores em relação à saúde deixa clara a relação dialética existente entre a saúde, o trabalho e o ambiente. Porquanto, afirma-se que é no metabolismo entre o homem e a natureza que se dá a relação entre o processo de trabalho e o biopsíquico humano. Ao se apropriar da natureza, o Homem a transforma, e transformando-a, transforma a si mesmo de tal modo que esta ação, incidindo sobre o objeto de trabalho, por meio de uso de instrumentos, configura o próprio trabalho, com suas diferentes formas de organização e divisão como característica de cada formação social (MARX, 2013). Sustenta-se, portanto, a assertiva segundo a qual o trabalho não é absolutamente externo ao homem (LACAZ, 1996; LAURELL; NORIEGA, 1989). Agindo sobre a natureza (externa), ele modifica a sua própria natureza (interna). Decerto, não se trata de uma dualidade, visto que "não podemos transformar a nós mesmos sem transformar o que se passa a nosso redor" (HARVEY, 2013B, P. 114) e vice-versa. Tratase de uma interação dialética profunda, entre homem, natureza, trabalho e vida (HARVEY, 2013B).

Ressalte-se que, como lembra Laurell (1981), existe uma interação entre o trabalhador, o objeto e o grau de controle que se pode exercer. Consoante Lacaz (1996), a categoria saúde, na perspectiva do campo das relações saúde e trabalho, excede as fronteiras de uma visão restrita entre ambiente e seus agentes ou da interpretação da saúde como adaptação. Configura-se, assim, uma tradição de pensamento crítico sobre a relação saúde e trabalho, sucedida na linhagem do marxismo, na qual o trabalhador é considerado sujeito ativo de transformação da matéria e da história, não sendo passivo ante a organização e o sofrimento no contexto de trabalho.

Desse modo, corrobora-se a afirmação categórica existente na teoria marxista de que "o trabalho é [...] eterna necessidade natural de mediação do metabolismo entre homem e natureza e, portanto, da vida humana" (MARX, 2013, P. 120). Assim sendo, é imperativo se desenvolver uma teorização que investigue as articulações internas dessa relação e que permita ao trabalhador perceber a profundidade dessa ligação na sua vida. Nessa abordagem, assegura-se 
que os processos de trabalho não são apenas contextos externos da saúde, mas, sim, fatores condicionantes conforme preconizado pela medicina social latino-americana (POSSAS, 1981; LAURELL; NORIEGA, 1989).

O pensamento de Harvey (2013B) reafirma esse pressuposto marxista, segundo o qual não existe separação no trabalho entre homem e natureza; cultura e natureza; mental e físico. Portanto, identifica-se nesse enfoque uma concepção unitária e dialética de processo de trabalho e natureza, na qual prevalece a ideia de que os seres humanos, por meio de seu trabalho, lançam-se por inteiro no processo, engajando a sua "corporeidade: seus braços e pernas, cabeça e mãos" (HARVEY, 2013B, P. 114). Convergente com essa acepção, Lukács (2015), fazendo referência a Marx, afirma que o metabolismo dialético entre homem e a natureza aparece, primeiramente, como condição natural eterna da vida humana e que esta sempre consistiu na atividade produtiva humana. Contudo, para que se entenda isso corretamente, de modo dialético e concreto, o autor destaca que Marx, em primeiro lugar, assegura que essa unidade se refere ao processo de trabalho em seus elementos simples e destaca o ponto central a ser considerado, na análise dos processos de trabalho, qual seja, o trabalhador em sua relação com outros trabalhadores. Parece, portanto, acertada a afirmação de acordo com a qual, no campo da saúde do trabalhador, é essencial se conhecer a relação entre as pessoas no processo de trabalho, ou seja, as relações que elas estabelecem para produzir, como nas palavras do próprio Marx:

Para produzir, eles assumem determinadas relações e determinados vínculos uns com os outros, e somente no quadro dessas relações e desses vínculos acontece sua relação com a natureza, acontece a produção. (MARX APUD LUCKÁCS, 2015, P. 89).

Outra proposição teórica de cunho marxista, complementar à tese da interação metabólica, que possui valor capital, no que diz respeito à compreensão da categoria saúde no campo da saúde do trabalhador, é aquela desenvolvida por Marx (2013) e retomada por Garcia (1989) que se refere ao papel do trabalho na transformação do homem. Convergente com essa acepção, o trabalho útil, criador de 'valores de uso' (MARX, 2013), suscita o desenvolvimento das capacidades físicas e mentais do ser humano, constituindo-se assim como um produtor de saúde. $\mathrm{O}$ ponto que se quer realçar é aquele segundo o qual a saúde é definida como

o máximo desenvolvimento das potencialidades do homem, de acordo com o grau de avanço obtido pela sociedade em um período histórico determinado. (GARCIA, 1989, P. 103).

Ao contrário, quando não existem as condições objetivas e subjetivas para que o trabalho seja estímulo das potencialidades, este pode converte-se em um produtor de doenças. Consoante a vertente da economia política de traço marxista, afirma-se que é por intermédio do trabalho que o homem desenvolve as suas potencialidades adormecidas e sujeita o jogo de suas forças ao seu próprio domínio (MARX, 2013). Segundo esse ponto de vista, sobressaem a autonomia e a criatividade, no trabalho, como tópicos essenciais da produção de saúde. Tratase de uma perspectiva na qual produzir saúde significa garantir condições favoráveis no trabalho para o desenvolvimento de potencialidades humanas.

Ao considerar a concepção da determinação social da saúde, cabe o reconhecimento de que o processo saúde-doença é histórico e, por conseguinte, mutável. Em verdade, a saúde assume formas históricas específicas, o que reafirma a necessidade de gerar conhecimento acerca de processos de trabalho localizados para a resolução de problemas de maneira a contribuir para a defesa da saúde.

Assim sendo, para a compreensão da saúde, parte-se da análise do processo de trabalho em articulação com o contexto histórico 
objetivando-se explicar as formas de adoecimento como expressão dos antagonismos e contradições sociais. Confirmando-se, assim, a formulação dialética presente nos escritos d'O Capital (MARX, 2013) de que a saúde está em permanente interação com o contexto de trabalho. Não há um trabalho neutro, exterior a nós: "O que fazemos lá fora tem muito a ver conosco aqui dentro" (HARVEY, 2013B, P. 117).

\section{$O$ processo de trabalho e a saúde sob limites do Capital: a tese da resistência dos trabalhadores}

Confirmou-se, nas publicações do campo da saúde do trabalhador, a centralidade do trabalho como categoria analítica essencial para se compreender a saúde, com destaque para o conceito de 'processo de trabalho' (LACAZ, 1996, 2007; MINAYO-GOMEZ, 2011; MINAYO-GOMEZ; THEDIM, 2003; MENDES;DIAS, 1991). Tal conceito, extraído da economia política em sua acepção marxista, permite que se apreendam as questões relativas à saúde dos trabalhadores em toda a sua complexidade (MINAYO-GOMEZ; THEDIM, 2003). Minayo-Gomez e Lacaz (2005) chegam a afirmar que esse conceito passou a ser o marco definidor do que se denomina por campo de estudos da saúde do trabalhador. Para Marx, a essência do trabalho situa-se na configuração do seu processo, ou seja, o trabalho constitui-se como 'processo' - como ação e transformação - e dessa forma deve ser analisado (HARVEY, 2013B).

No que tange à questão das categorias analíticas no campo das relações saúde e trabalho, Laurell e Noriega (1989) chamam atenção para o ponto referente à necessidade de selecionar referenciais empíricos, de tal ordem que se coloque o problema da hierarquia das categorias analíticas, situando 'processo de trabalho' como de maior valor. É essencial, para tanto, que se construam categorias teóricas tecendo a articulação necessária entre o concreto (análise do processo de trabalho) com a totalidade, lançando-se mão do exercício dialético de interpretação do real (HARVEY, 2013B). Para Laurell e Noriega (1989), a perspectiva da saúde do trabalhador se traduz, particularmente, em apreender a relação entre produção e saúde sob um enfoque teórico diverso da maneira positivista de conceituá-lo, pois, de acordo com essa visão, o processo de trabalho é compreendido não como uma sucessão inalterável de acontecimentos, mas como situações em permanente mudança; uma relação entre trabalhadores e produção como um metabolismo vivo.

De fato, a conformação do processo de trabalho é um dos elementos-chave para a compreensão dos determinantes da saúde do trabalhador, já que permite extrair de que forma se constitui o vínculo concreto entre o trabalho e a saúde. Por meio de sua análise, é possível averiguar as formas particulares de organizar e dividir o trabalho (LAURELL; NORIEGA, 1989, P. 175). Um dos aspectos que tange a organização e divisão do trabalho envolve formas de controle, hierarquia, ritmos, duração da jornada, trabalho em turnos, a fragmentação e conteúdo das tarefas e as exigências, entre outras (LACAZ, 2007).

Além disso, Gomez e Lacaz (2005) asseguram que a análise dos processos de trabalho é uma ação teórico-prática vigorosa, pois permite identificar as transformações necessárias a serem introduzidas nos locais e ambientes para melhoria das condições de trabalho e saúde, o que requer uma ação interdisciplinar realizada por equipe de pesquisadores de diversas áreas de conhecimento, com a necessária participação dos trabalhadores e suas organizações. Todavia, ressalte-se, como lembram os autores, que o conceito de processo de trabalho foi concebido originalmente para interpretar o trabalho industrial, demandando esforço para que se construam outras categorias explicativas complementares de modo a alcançar a diversidade do amplo e complexo universo de trabalho.

Assim, compartilha-se a tese de que os elementos concretos no processo de trabalho são elementos essenciais para a 
interpretação da saúde. Isso significa afirmar que a defesa da saúde está organizada e materializada, antes de tudo, no trabalho diário, de maneira localizada, e que mantém relação com o controle do processo de trabalho. Nessa linha de compreensão, questiona-se a organização capitalista e as suas formas de exploração, sendo que o espaço concreto de produção é o cenário primário da exploração e da confrontação de classes (LAURELL; NORIEGA, 1989, P. 23). Além do mais, não se pode olhar para o processo de trabalho como um processo puramente físico. É necessário conhecer o contexto das relações sociais, considerando o modo como o capitalismo faz uso peculiar das capacidades dos trabalhadores (HARVEY, 2013B, P. 121).

Importa, então, desvendar a nocividade do processo de trabalho sob o capitalismo e suas implicações: alienação; sobrecarga e/ou subcarga; pela interação dinâmica de 'cargas' sobre os corpos que trabalham, conformando um nexo biopsíquico que expressa o desgaste impeditivo da fluição das potencialidades e criatividades. (LACAZ, 2007, P. 760).

O ponto que se quer realçar diz respeito ao trabalho como atividade humana; como atividade orientada para um fim, base da criatividade (MARX, 2013). Fato é que, quando a potencialidade humana tende constantemente a ser negada, é o momento em que o trabalho assume a forma explorada e alienada. Esse seria um dos motivos pelo qual o processo de trabalho converte-se em um campo pleno de contradições, daí decorre que os trabalhadores venham a desenvolver uma resistência contra sua própria desumanização, que se manifesta na astúcia e na "mão rebelde do trabalho" (LAURELL; NORIEGA, 1989, P. 104).

Sob a égide do capitalismo, segundo Harvey (2013A), o trabalhador pode familiariza-se com a degradação do trabalho, não produzindo estranhamento para o fato de que as suas habilidades e criatividade sejam constantemente negadas. Destarte, deve-se estar atento para as transformações ocorridas no mundo do trabalho e os seus resultados sobre as relações humanas, pois, conforme assegura Sennett (2002), o chamado 'Capitalismo Flexível' produz consequências sobre 0 caráter pessoal dos trabalhadores. Pede-se a eles agilidade, abertura a mudanças e que estejam, continuamente, preparados para assumir riscos. Em seus estudos, Sennett (2002) observou que a flexibilidade e o novo modo de operar do trabalho no capitalismo causam ansiedade permanente nas pessoas, abrindo-se mão de valores duradouros como a solidariedade, a confiança, a lealdade e o compromisso mútuo. Segundo o autor, esses laços sociais levam tempo para surgir, em contraste com a dimensão do tempo no novo capitalismo, que se constitui como de curto prazo. Para Sennett (2002), essa característica atual do capitalismo (curto prazo) corrói o caráter das pessoas, especialmente, aquelas qualidades (de caráter) que ligam os seres humanos uns aos outros.

Mendes e Dias (1991) afirmam que, na perspectiva da saúde do trabalhador, considera-se o trabalho como o espaço de dominação e submissão do trabalhador pelo capital, mas também de resistência e do fazer histórico, possibilitando, pela experiência de classe, o controle sobre as condições e o ambiente de trabalho.

Por conseguinte, é também no processo de trabalho que se dá o enfrentamento de classe em termos de estratégia e de resistência. Laurell e Noriega (1989) afirmam, de forma categórica, que se deve apreender a relação saúde e trabalho por uma compreensão integral do processo de trabalho à medida que não é tal ou qual risco que faz adoecer, mas, sim, o conjunto dos elementos presentes ao processo de trabalho.

É interessante observar nos textos de Marx (2013) e de Harvey (2013A, 2013B), a respeito da categoria processo de trabalho, que se trata de um debate de caráter muito atual e essencial para se entender a dinâmica relação entre saúde e trabalho. Para Harvey (2013A), a luta de classes e as resistências existentes 
no próprio processo de trabalho são pontos vitais para entender como os trabalhadores enfrentam e tornam suportável, individual e coletivamente, o processo de trabalho. Existe, de acordo com essa perspectiva, uma guerrilha permanente entre capital e trabalho que se processa no 'chão de fábrica' e no cotidiano de trabalho.

Pode-se afirmar que, no tocante à saúde, os trabalhadores estão de modo permanente sob pressão e entre limites (HARVEY, 2013A), nenhuma estratégia parece inteiramente viável e, por isso, as relações sociais no trabalho envolverão, continuamente, equilíbrio e tensão. Sobre essa base de compreensão, é imperativo entender como os trabalhadores se organizam para sua autodefesa e para defesa coletiva da sua saúde dentro dos locais de trabalho, gerando as condições necessárias para torná-lo espaço de contestação e resistência. Desse modo, reafirma-se o local de trabalho como base para lutas políticas mais amplas. Sennett (2002) assevera a importância de reaver a dimensão coletiva da vida no trabalho, porquanto uma das consequências, não pretendidas do capitalismo moderno, foi o fortalecimento do valor do lugar, da comunidade de trabalho. Consoante Sennett (2002), é quase que uma lei universal que o 'nós' pode ser usado como defesa contra as formas de acometimento do capital e pergunta: "Que espécie de partilha é necessária para resistir, em vez de fugir, diante da nova economia política?" (SENNETT, 2002, P. 166).

Quanto à interpretação de Harvey (2013A) acerca de processo de trabalho, sobressai a tese de que o trabalhador é sujeito criativo que luta e resiste às deteriorações do capital, tornando-se assim protagonista de sua própria história. Segundo Harvey (2013B), Marx confere ao processo de trabalho uma dimensão nobre do trabalho criativo que é, precisamente, a transformação do mundo pelas próprias mãos dos trabalhadores, exercendo uma interação dialética entre ação e resistência no processo de trabalho.

\section{Organização, participação e experiência dos trabalhadores: a tese relativa à saúde como práxis}

Uma das teses centrais, encontrada na literatura do campo da saúde do trabalhador, é aquela de acordo com a qual a explicação da saúde dos trabalhadores está estreitamente relacionada com a sua capacidade organizativa, como sujeitos coletivos (LAURELL; NORIEGA, 1989; LACAZ, 1996).

Convém destacar que o conceito de práxis na tradição de pensamento do materialismo histórico se traduz como atividade 'prático-crítica' e deve proferir, em última análise, a transformação do próprio homem e de seu mundo histórico. A transformação da realidade não se faz mediante um trabalho em nível puramente intelectualista, mas sim na práxis verdadeira, que demanda ação constante sobre a realidade e a reflexão permanente sobre esta ação (MARX; ENGELS, 1986).

Em que pese o enfraquecimento dos movimentos e das lutas dos trabalhadores no atual cenário político, a valorização e a defesa da saúde vão depender do poder de organização política e de luta dos trabalhadores, revelando o seu caráter histórico (LACAZ, 1996). De acordo com Engels (1974, P. 334),

todas as lutas históricas quer se processem no domínio político, filosófico ou qualquer outro campo ideológico, são na realidade a expressão, mais ou menos clara, de lutas e conflitos entre classes sociais.

À guisa de ilustração, Berlinguer, nessa mesma linha de compreensão, reitera a ideia de Hipócrates que afirmou que "a saúde é fraca onde os homens não são senhores de si mesmos e das próprias leis" (HIPÓCRATES APUD BERLINGUER, 1983, P. 57).

Laurell (1993) afirma que a participação efetiva dos trabalhadores por meio de suas 
organizações pode gerar impacto relevante na realidade de saúde. Observa-se, na literatura do campo, uma inquietação permanente para que se criem as condições favoráveis, teórico-metodológicas e práticas, de modo a construir a crítica coletiva, a produção de conhecimento e a ação para se transformar a realidade, base do postulado da décima primeira tese de Marx sobre Feuerbach (MARX; ENGELS, 1986, P. 14): "Os filósofos se limitaram a interpretar o mundo de diferentes maneiras; o que importa é transformá-lo".

Depreende-se dos escritos da medicina social latino-americana a afirmação categórica consoante a qual a luta pela saúde se situa no terreno do confronto entre capital e trabalho e aflora no âmbito do próprio processo de trabalho, apontando para a necessidade de apoiar as reivindicações dos trabalhadores e suas organizações com estudos que mostrem os efeitos nocivos do trabalho. Nas palavras da autora:

O primeiro elemento que deve ser levado em conta na análise de qualquer processo de trabalho particular são então, as expressões concretas da luta de classes e o grau concreto de controle que os operários exercem sobre o processo de trabalho. (LAURELL, 1981, P. 10).

Não obstante, Garcia (1989) observa que a luta do movimento organizado dos trabalhadores pode contribuir para a redução do adoecimento relacionado com as condições de trabalho, no entanto não faz desaparecer as que resultam do próprio processo de trabalho no capitalismo.

Distingue-se nessa vertente (LAURELL; NORIEGA, 1989; ODDONE ET AL, 1986) a tese da necessidade de formalizar o saber operário, possibilitando que a experiência no trabalho se torne conhecimento a partir da relação que se constrói entre trabalhadores e pesquisadores. Berlinguer (1983) afirma que muitas situações ocupacionais nocivas só podem ser detectadas por meio do relato dos trabalhadores, mediante o seu saber. Portanto, na perspectiva da saúde do trabalhador, não existe a preponderância do saber técnico sobre os trabalhadores, mas, sim, a coletivização das experiências para construir um caminho mais rico e concreto no trabalho, abrindo-se alternativas para a superação do isolamento cultural e político em que se encontram as esferas do trabalho e da ciência (ODDONE ET AL., 1986; BERLINGUER, 1983).

A originalidade dos estudos italianos (BERLINGUER, 1983; ODDONE ET AL., 1986) consiste precisamente no aspecto relativo à participação dos trabalhadores como essencial para a melhoria das condições de trabalho. Os conceitos de "não delegação', 'validação consensual' e 'grupo operário homogêneo' são parte de um patrimônio da cultura operária que articula a dimensão técnica, política e ideológica da temática saúde e trabalho na qual o trabalhador é seu sujeito e protagonista, individual e coletivo. Por conseguinte, o seu ponto de vista e o seu saber constituem-se como parte, essencial, do conhecimento científico (ODDONE, 2007).

Nas objeções de Berlinguer (1983), a respeito do conceito de saúde, tem precedência o critério da avaliação não somente individual, mas de grupo, de classe, e não somente imediata, mas enriquecida com dados científicos (P. 49). O conhecimento deve ser continuamente socializado e submetido à verificação coletiva. Trata-se de uma concepção (dialética) de saúde como práxis.

\section{Considerações finais}

Segundo a perspectiva aqui apresentada, poder-se-ia afirmar que a categoria saúde, no ponto de vista do campo da saúde do trabalhador e no contexto do atual modo de produção, não se constituiu em um valor dado, mas sim a ser conquistado por luta, como práxis. Encontra-se em permanente tensão no âmbito da história, já que está no cerne das contradições entre os desígnios do poder econômico do capital e as possibilidades de transformação da realidade. Daí a afirmativa 
consensual no campo segundo a qual a saúde nessa perspectiva é fortemente determinada pelas condições sociais e pela capacidade organizativa dos trabalhadores (LAURELL; NORIEGA, 1989; GARCIA, 1989; LACAZ, 1996)

A linhagem do campo de conhecimento das relações saúde e trabalho que adota os preceitos da medicina social latino-americana e dos estudos operários italianos influenciam ainda hoje, sobremaneira, a configuração teórico-metodológica da saúde do trabalhador. Trata-se de uma genealogia filosófica advinda do materialismo histórico que postula a consolidação de um campo de conhecimento militante, no qual ocupam posição de destaque os processos de produção compartilhada de conhecimento, entre pesquisadores e o coletivo de trabalhadores. Conclui-se que a categoria saúde nessa perspectiva encontra-se profundamente conectada com a ideia de promover processos de lutas, movimentos de defesa da saúde em articulações com as organizações de trabalhadores.

Em termos históricos, afirma-se a capacidade explicativa das categorias marxistas para análise do trabalho, em especial a de 'processo de trabalho'. Além disso, enfatiza-se a imperiosa necessidade da organização por locais de trabalho, "estratégia que se impõe em qualquer projeto que se pretenda transformar condições e ambientes de trabalho" (LACAZ, 1996, P. 411). Contudo, sabe-se das profundas transformações decorrentes da lógica produtiva e das constantes mudanças ocorridas na atual configuração das relações de trabalho, como o caso das terceirizações e outras formas de trabalho precário (MINAYO-GOMEZ, 2011), o que impõe o desafio de constantes atualizações dos referenciais do campo de maneira a produzir conhecimento, dialeticamente, em estreita correlação com a transformação da realidade.

\section{Colaboradores}

O primeiro autor participou da concepção, redação e interpretação dos materiais do manuscrito; o segundo e terceiro autores contribuíram, igualmente, na elaboração do texto e revisão crítica do conteúdo do ensaio; quanto ao quarto autor, contribuiu com a redação final e participou da aprovação da versão final do manuscrito.

\section{Referências}

ANTUNES, R. Os sentidos do trabalho: ensaio sobre a afirmação e a negação do trabalho. São Paulo: Boitempo, 2009.

BERLINGUER, G. A saúde nas fábricas. Rio de Janeiro: Cebes; São Paulo: Hucitec, 1983.

ENGELS, F. Prefácio de Engels para a terceira edição alemã. In: MARX, K. O dezoito Brumário de Luís

Bonaparte. Rio de Janeiro: Paz e Terra, 1974.
GARCÍA, J. C. A categoria trabalho na medicina. In: NUNES, E. D. (Org.). Pensamento social em saúde na América Latina. São Paulo: Cortez, 1989. p. 100-124

HARVEY, D. Os limites do Capital. São Paulo: Boitempo, 2013a.

Para entender o Capital. São Paulo: Boitempo, 2013b. 
LACAZ, F. A. C. O campo Saúde do Trabalhador: resgatando conhecimentos e práticas sobre as relações trabalho-saúde. Cad. Saúde Pública, Rio de Janeiro, v. 23, n. 4, p. 757-766, 2007.

Saúde do trabalhador: um estudo sobre as formações discursivas da academia, dos serviços e do movimento sindical. 1996. 432 f. Tese (Doutorado em Saúde Coletiva) - Universidade Estadual de Campinas, São Paulo, 1996.

LACAZ, A. C.; SANTOS, A. P. L. Saúde do Trabalhador, hoje: re-visitando atores sociais. Revista Médica de Minas Gerais, Belo Horizonte, v. 20, n. 2, supl. 2, 2010.

LAURELL, A. C. Para La investigación sobre La salud de los trabajadores. OPA; OMS, 1993. Disponível em: $<$ https://www.google.com.br/url?sa=t\&rct=j\&q=\&esrc= s\&source=web\&cd=1\&ved=0ahUKEwjHtv78t4vUAhU EGZAKHWmdDNIQFggoMAA\&url=http\%3A\%2F\%2F iris.paho.org\%2Fxmlui\%2Fbitstream\%2Fhandle\%2F12 3456789\%2F3293\%2FPara\%2520la\%2520investigaci\% 25F3n\%2520sobre\%2520la\%2520salud\%2520de\%252 0los\%2520trabajadores.pdf\%3Fsequence\%3D1\&usg=A FQjCNFfYUKzMDBJ7vIRErQXoN-hBbiZgg\&sig2=lq7 jmwIW6bq5r4z9EXQmnQ>. Acesso em: 9 fev. 2016.

Processo de trabalho e saúde. Saúde em Debate, Rio de Janeiro, n. 11, p. 8-22, 1981.

LAURELL, A. C; NORIEGA, M. Processo de produção e saúde: trabalho e desgaste operário. São Paulo: Hucitec, 1989.

LUKÁCS, G. Reboquismo e dialética. São Paulo: Boitempo, 2015.

MARX, K. O Capital. São Paulo: Boitempo, 2013. v. 1.

MARX, K.; ENGELS, F. A ideologia alemã. 5. ed. São Paulo: Hucitec, 1986.

MENDES, R.; DIAS, E. C. Da medicina do trabalho à saúde do trabalhador. Rev. Saúde Públ., São Paulo, v. 25, n. 5., 1991.

MINAYO-GOMEZ, C.; Campo da saúde do trabalhador: trajetória, configuração e transformações. In: MINAYO, C. G. et al. (Org.). Saúde do trabalhador na Sociedade Brasileira Contemporânea. Rio de Janeiro: Fiocruz, 2011. p. 23-34.

\section{MINAYO-GOMEZ, C.; LACAZ, F. A. C. Saúde do} trabalhador: novas-velhas questões. Ciência \&t Saúde Coletiva, Rio de Janeiro, v. 10, n. 4, p. 797-807, 2005.

\section{MINAYO-GOMEZ, C.; THEDIM, S. M. F. Incorporação} das ciências sociais na produção de conhecimento sobre trabalho e saúde. Ciência \&\& Saúde Coletiva, Rio de Janeiro, v. 8, n. 1, p. 125-136, 2003.

ODDONE, I. et al. Ambiente de trabalho: a luta dos trabalhadores pela saúde. São Paulo: Hucitec, 1986.

Reflexiones sobre el modelo obrero italiano.

Revista Sindical Salud, Trabajo y Medio Ambiente, Lima, v. 2 , n. 5 , p. $4-8.2007$.

POSSAS, C. Saúde e Trabalho. Rio de Janeiro: Graal, 1981.

SENNETT, R. A corrosão do caráter: consequências pessoais do trabalho no novo capitalismo. Rio de Janeiro: Record, 2002.

Recebido para publicação em julho de 2016

Versão final em janeiro de 2017

Conflito de interesses: inexistente

Suporte financeiro: não houve 